\section{SPEECH, HANDEDNESS AND CEREBRAL DOMINANCE}

\section{Cerebral Dominance and its Relation to Psycho- logical Function}

By Prof. O. L. Zangwill. (The Henderson Trust Lectures, No. 19.) Pp. vii +31 . (Edinburgh and London: Oliver and Boyd, Ltd., 1960. Published for the William Ramsay Henderson Trust.) $10 s .6 d$. net.

DROF. ZANGWILL'S book embodies the William Ramsay Fenderson Trust lectures, and it is pleasant to note, though he never alludes to the fact, that the object of the Trust is: "The advancement and diffusion of the science of phrenology". It could be argued indeed that the phrenologists are still with us, for there are still plenty of people ready to locate supposed psychological faculties in particular areas of the brain. Indeed, the idea of cerebral dominance and handedness implies some form of localization. if only in respect of the cerebral hemispheres, and Prof. Zangwill's object is to discover exactly what this means. The lectures are largely a summary of the work previously published by himself and his collaborators. As he frankly says, "these studies of speech and handedness unfortunately raise far more problems than they solve". Already, however, we must recognize that there is no clear-cut division into righthanded persons with a dominant left cerebral hemisphere and left-handers with a dominant right hemisphere. On the contrary, "in left-handed or predominantly left-handed patients, the dominant hemisphere as conventionally ascertained is more often the left than the right. Furthermore, left hemisphere dominance may even occur in sinistrals who have always written with the left hand". This has certain implications for the study of aphasia, for there is now evidence that recovery from aphasia tends to be more complete in patients who are lefthanded or who have left-handed relatives than in those who are fully right-handed, perhaps because unilateral specialization of the language functions in the brain appears to vary between individuals, being as a rule far more pronounced in right-handed than in left-handed subjects.

Prof. Zangwill goes on to study the significance of these facts for the understanding of specific backwardness in reading and spelling. In 75 per cent of his cases there is evidence of some sinistral tendency in the individual or in his family. Mixed or inconsistent hand preference was common, and uncomplicated dextrality rare. He suggests, also, that socalled specific defects in reading and spelling are seldom present in isolation, and are commonly embedded in a more complex developmental syndrome.

For many years now evidence has been accumulat. ing that even in clear-cut right-handedness there are important differences of function between the right and left cerebral hemispheres, and that the left hemisphere, which is dominant in such people, is not merely a mirror image of the right with the addition of functions concerned with symbolic formulation and expression. Some independent evidence of this has recently been provided by studies of sensory disturbances after penetrating brain-wounds in man (Somato-sensory Changes after Penetrating Brain Wounds in Man, by J. Semmes, S. Weinstein, L. Ghent and H. L. Teuber, Oxford University Press). It has been found that sensation of the left hand is more diffusely represented in the right cerebral hemisphere than is that of the right hand in the left. Similar observations have been made in many fields of discriminative activity. As yet these remain isolated observations, and we have not reached the stage at which any broad generalization can be inferred from them. Prof. Zangwill's book is a useful summary of the present state of our knowledge of the relationship between speech, handedness and cerebral dominance.

Russell Bratn

\section{BACKGROUND TO ASTRONOMY}

The Fabric of the Heavens

By Stephen Toulmin and June Goodfield. (Nuffield Foundation Unit for the History of Ideas. The Ancestry of Science, Vol. 1). Pp. $272+14$ plates. (London: Hutchinson and Co. (Publishers), Ltd., 1961.) 25s, net.

$\mathrm{H}$ ISTORY of science is at present expanding at university-level so rapidly that lectureships are sometimes left vacant for want of suitably trained lecturers to fill them. At school-level the subject is also expanding, but here another limiting factor is the shortage of suitable books.

The present work is that of a series which will do much towards alleviating the shortage. It is a survey of the interlinked history of astronomy and mechanics from earliest times to Newton, with a further outline bringing the story to the present day. It is to be followed in the next few months by no less than three more volumes, each dealing with a major field of history and philosophy of science. One might feel that a lifetime of teaching and research would alone qualify an author for attempting any one of these volumes, but there is a special urgency in history of science and a worthwhile place for general books which give some inkling of the excitement of the subject.

This The Fabric of the Heavens certainly does. It is written with fluency and conviction, and the reader never loses interest. There are, however, many signs of the haste with which it was writtenalong with the relevant illustrations we find a photograph of the port of Pythagoreon and snapshots of a Greek temple taken from different angles-as well as a number of confusions and serious errors of fact. Thus the authors ascribe the discovery of the planet Uranus in 1781 to John Herschel (born 1792) and quote William Herschel (died 1822) as congratulating Bessel on his discovery of stellar parallax in 1837; yet a philosopher of science like Dr. Toulmin must know John Herschel's 1830 Preliminary Discourse on the Study of Natural Philosophy, and in writing their promised The Flux of Nature the authors must surely be studying the cosmogony of William Herschel. Samuel Clarke, who in fact believed gravity to be a "connate and original law of all matter... We ought no more to enquire how bodies gravitate than how the world began to move" is described as protesting "that some push-and-bang mechanism must eventually be discovered for gravity". Galileo, we are told, "did not study freely falling bodies directly". Copernicus's elimination of the equant is discussed in the context of his general cosmology, although the question does not properly arise until we come to his detailed mathematical astronomy; here the role of neo-Platonism in Copernicus's thought is hopelessly underrated, and although highly dispar- 